1879 Col. Rykatchoff, of the St. Petersburg Central Physical Observatory, established, on board the Nayezdnik. an anemometer of his own construction, which was observed during the ocean cruise of the clipper; and the schooner Nordenskjöld, which unhappily was lost in 1879 at Yesso Island, had also an anemometer, which was taken afterwards on board the Russian clipper Djighit by $M$. Domojirov. The observations on board of the Djighit were carried on with this anemometer (of Casella) put in such an apparatus (like that of the lamps on board of ships), as always maintained it in a vertical position, even during the heaviest seas, when the ship oscillated for $30^{\circ}$ on one side, and $35^{\circ}$ on the other. The apparatus was put on a 16 -foot-long pole, which was pushed out for each observation on the wind-side of the ship, from the boat, and thus exposed to the full force of the wind for ten minutes. The height of the instrument above the sea was 26 feet. The direction of wind was determinated by means of a vane, and its true direction computed from the apparent one, on the principle of the parallelogram of forces, by taking into account the velocity of the ship. When the angle between the direction of the wind and the direction in which the ship goes is known, as well as the seeming velocity of wind (measured by the anemometer), and the velocity of the ship, the true velocity of wind is easily determined by means of simple computations, or of the tables published for that purpose by M. Rykatchoff (Russian Marine Review, February, 1880). A series of experiments having been made for ascertaining in how far the calculated figures agree with the true ones, M. Domojirov arrives at the conclusion that these figures are quite reliable; determination having been made during the progress of the ship, she was immediately stopped, and the determination made anew, both results always being quite identical. But the measurements from the side-boat are very tedious and even dangerous during heavy seas, and each observation occupies no less than three men for about twenty minutes. Therefore M. Domojirov proposes to apply electricity to register the rate of the anemometer.

The observations on board the Djighit were made five and six times per day from March 23 to May 30 , and the complete results, with all elements for calculations, are published in the papers of M. Domojirov. The northeastern trade-wind, observed on the passage from Japan to the Sandwich Islands and back, had a very regular force of from 5 to 9 metres per second; the south-eastern trade-wind experienced on the passage from the Sunda Islands to the Seyschels, had a velocity of 4 to 9 metres per second, and the south-western winds on the passage from Port Victoria to Aden, had velocities from I2 to I5 metres per second.

It would hardly be necessary to insist on the importance of such observations for meteorology, as well as for practical purposes, and we hope that soon the still prevailing prejudices as to the possibility of anemometrical observations on board ships having disappeared, and more convenient methods of observaticn having been devised, the anemometer will become on board ships as necessary an instrument as the $\log$ and barometer.

P. K.

\section{INSTANTANEOUS PHOTOGRAPHY OF BIRDS IN FLIGHT}

$\mathrm{P}$

ROF. E. J. MAREY has lately published in the pages of our contemporary, La Nature, an article on a "photographic gun," the illustrations to which, with a somewhat shortened account of the process, we are enabled, through the courtesy of the editor of La Nature, to present to our readers. M. Marey's researches on animal locomotion are well known; his experiments carried on by the graphic method were productive of most valuable results, and they corrected and explained many debated points in animal mechanics; but having seen some of the results obtained by Mr. Muybridge, at San Francisco, with photographic pictures taken during an exposure of the 1-500th of a second, he was very desirous to have the same process adapted, so as to admit of its being applied to the taking of birds flying. In September, 1881, on a visit of $\mathrm{Mr}$. Muybridge to Paris, he brought with him some photographs of birds taken on the wing, but these unlike the invaluable series taken by the same gentleman of horses and men, were not the representation of a series of continuous attitudes, but rather represented the bird in the position it happened to be in at a moment of time ; whereas, to explain the fall and rise of the wings and the positions of

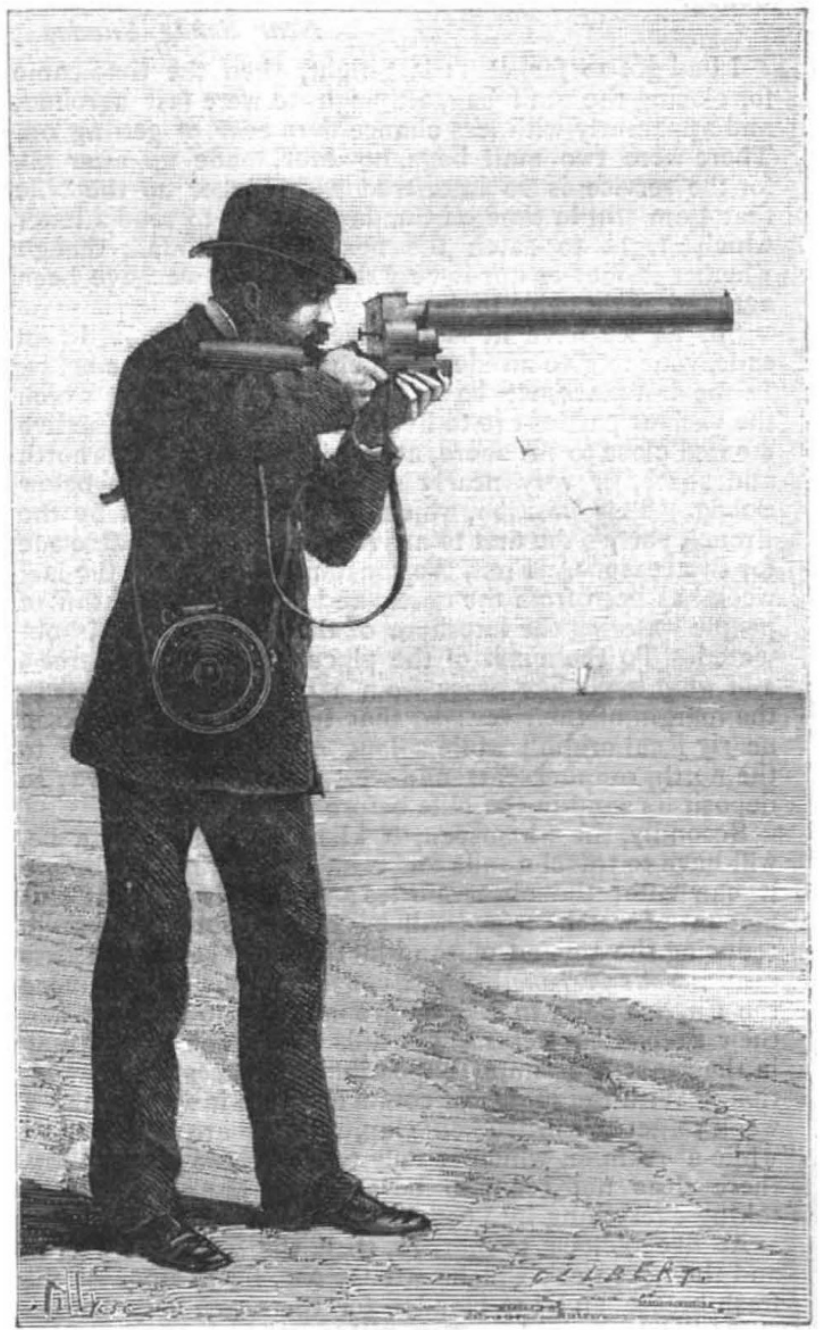

FIG. I.-The Photographic Gun.

the body, it was, above all things, important to have a series of rapid photographs taken of the same bird over a period during which the whole mechanism was in action, so as to allow of the movements to be afterwards studied at leisure. After deliberating over this subject during the last winter, at last the idea of a photographic gun occurred to him; but the immense quickness with which the movements should succeed one another, in order to bring a series of sensitive surfaces across the lens, at first presented great difficulties in the constructing of the machine. It was necessary to have images taken successively ten or twelve times in one second, in order to 
succeed in obtaining the various positions of the wings of twelve images, in one second, of an object on which the a bird at each revolution. As the result of a good deal piece was continuously sighted. The time of exposure af of thought and labour, an apparatus was constructed about each image was about 1-72oth of a second.

the size of a sporting-piece (Fig* I), which would take The barrel of the gun is a tube containing a photo-

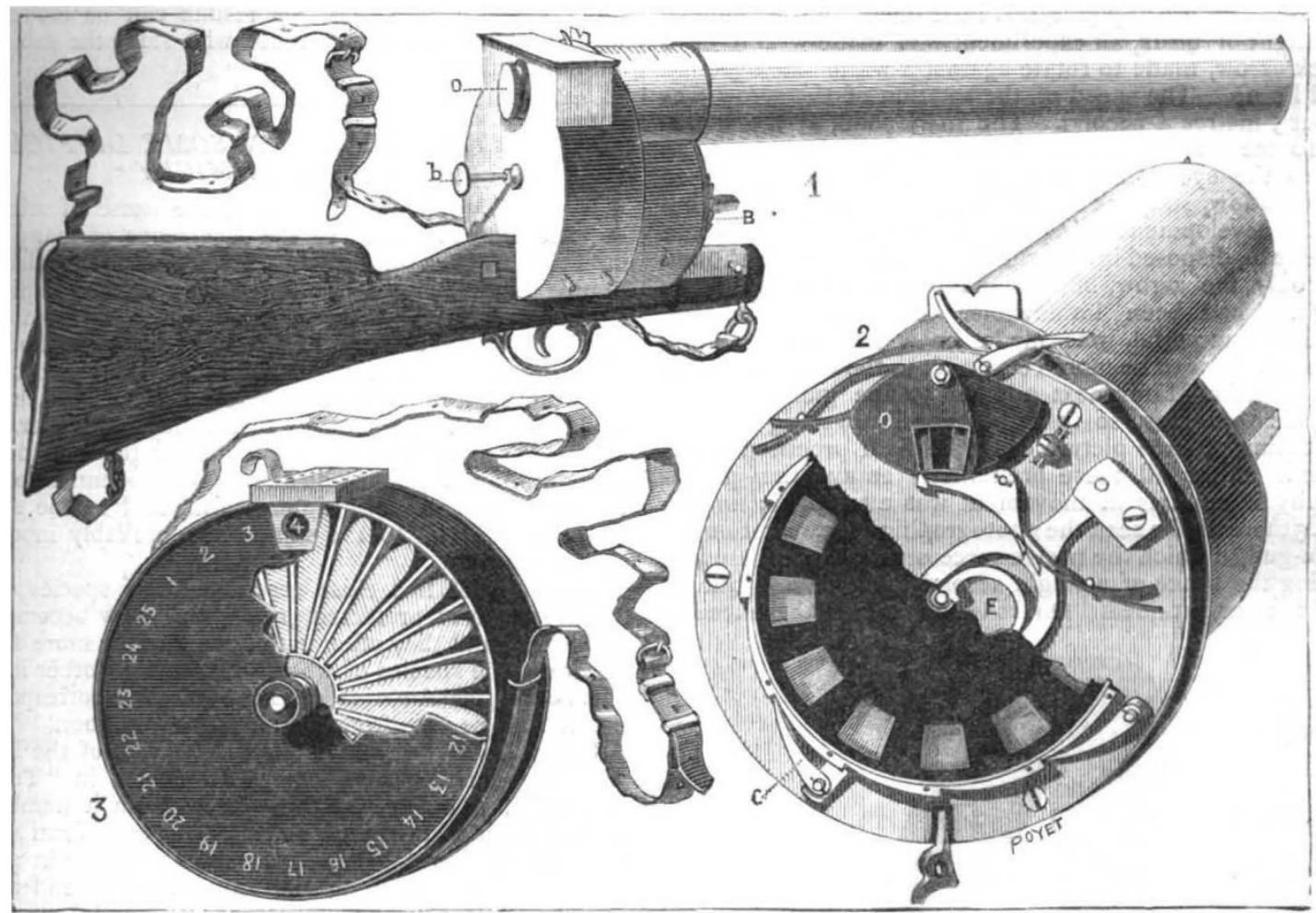

FıG. 2.-Mechanism of Gun. I, Ge:eral view; 2, Wincowed disc ; 3, Box with 25 sansitive plates.

graphic object-glass. Behind this, and solidly mounted/work is set in action, giving to the different parts on the butt, is a long cylindrical breach, containing clock-

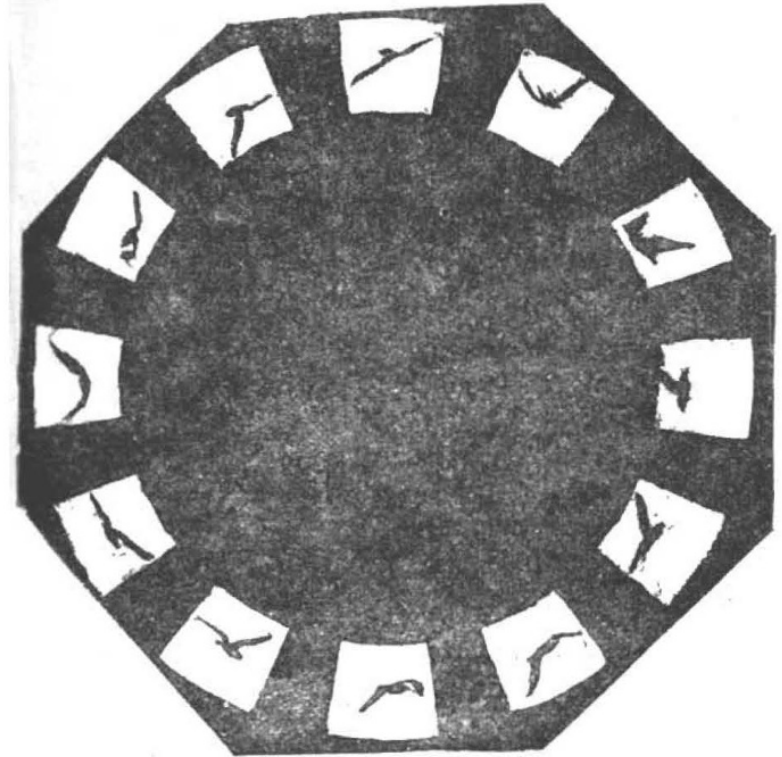

FIG. 3.-Sea-gull, flying; heliograph of twelve plates obtained by the process.

work, of which the exterior of the barrel is seen at $B$, Fig. 2, No. I. On pressing the trigger the clockof the instrument the necessary motion. A central axis, which makes twelve revolutions per second, governs all the pieces of the apparatus. Of these one is a disk of metal pierced with fine openings, which acts as a diaphragm, and only allows the image of the object to be presented twelve times in a second, and each time only

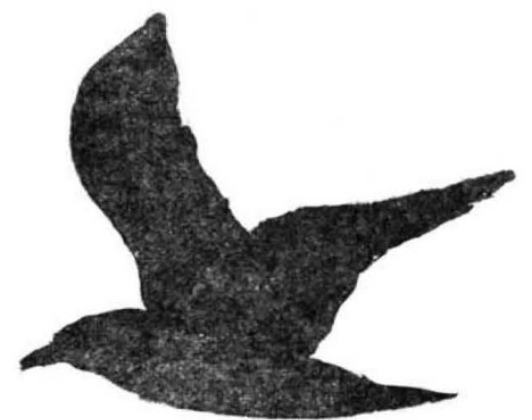

Fig. 4.-Sea-gull; beginning of depression of wing.

for I-720th of a second. Behind this, and revolving on the same axis, is another disk carrying twelve windows, behind which are the sensitised plates. This windowed disk revolves in such a way as to be slightly arrested in its course twelve times in a second, when the open windows are exposed to the light. The teeth to arrest its movements are seen at C, Fig. 2, No. 2, while the excentric at E, Fig. 2, No. 2, keeps up the regularity of this 
movement. A cover over all keeps the light out from the rear of the instrument. It will be noted that during the instant of exposure, the sensitised surface is steady, and when the exposure is over, it is at once passed away. Pressure on the button (b, Fig. 2,1$)$ sets the machine in motion. Before applying this instrument to the study of the flight of birds, an experiment was made with it on a black arrow, made to rotate against a white back-ground well lit up. The speed of the rotation of the arrow was about 5 metres a second. The marksman, at a distance of ro metres sighted on the centre of the target, on which the eye could perceive nothing save a confused grey shadow, so quick was the rotation of the arrow : but on the development being completed, twelve images were to be seen, disposed in a circular manner, and each showed not only the arrow, but its shadow, as sharp as if the original had been immovable. Another experiment, equally successful, was made on a pendulum beating seconds. For to be more certain as to the duration of the exposure, M. Marey next adapted to the gun a chronographic apparatus, so that the time intervening between the taking of each picture could be with precision ascertained. After all these preliminary essays, the photography of animals in movement was attempted; and in Fig. 3 there will be seen the photographic representations of a sea-gull, in which the twelve successive attitudes assumed during the space of a single second by this bird during flight are ascertained. On other occasions other success-

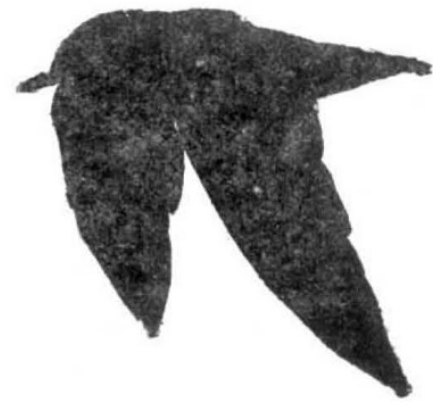

FIG. 5.-Sea.gull; end of depression of wing.

ful photographic series of a sea-gull in flight were taken when the bird was seen less in profile. The sea-gull gave exactly three strokes of its wing each second, so in the twelve photographs of each stroke four succeeding stages were reproduced. The wings at first elevated to their greatest, then commence to be lowered ; then in the following image they are seen at the lowest point of their course and in the fourth image are again on the rise. In enlarging these images, figures seen from a good distance were obtainable, but the sharpness of the enlargements left a good deal to be desired ; for the negatives were somewhat granular, no doubt owing to some slight fault in the photographic process. The reproduction of these images by the heliographic process gives excellent silhouettes (as seen in Figs. 4 and 5 ); the originals, when examined under the microscope, showed even the wing-feathers distinctly.

On comparing the indiations thus given by the photographic process with those already attained by the graphic process, a confirmation of most of the principal points obtained by the latter were obtained; but otherwise so far, the latter did not seem to add much to our knowledge of the mechanism of flying. However, ere deciding that this is so, numerous observations on different birds flying and in different conditions of flight, during calms and storms, and with and against the wind, must be taken. Attempts were also made to photograph the bat, but its small size, its flight during the dusk, and its capricious method of flying made it a difficult subject; but some of the experiments revealed interesting results. The angle of oscillation of its wings is very extended, especially from below, when the two wings form two vertical planes sensibly parallel.

These extremely interesting researches of M. Marey are only, as it were, in their infancy; he intends pursuing them much further, and his results will be looked for with great interest by all those who study the subject of animal motion.

\section{DR. FRITZ MÜLLER ON SOME DIFFICULT CASES OF MIMICRY}

I $\mathrm{N}$ his original explanation of the cause of mimicry, Mr. Bates referred to the occurrence of many cases in which species of different genera of Heliconidæ resemble each other quite as closely as the mimicking Leptalides and Papilios resemble species of Ithomia and other Heliconoid butterflies. In these cases both the imitating and the imitated species are protected by distastefulness, and it was not therefore clear how the one could derive any benefit by resembling the other. Accordingly, Mr. Bates did not consider these to be true cases of mimicry, but to be due, either to identical parallel variations of externally similar form, or "to the similar adaptation of all to the same local, probably inorganic, conditions."

Examples of this close resemblance of species of different genera of protected groups have now become very numerous, and they often extend to three or more distinct genera, some species of which imitate each other in most parts of tropical America, each changing in a corresponding: manner as we pass from one district to another.

In my Address to the Biological Section of the British Association at Glasgow, in 1876 (reprinted in "Tropical Nature"), I connected these cases with a number of others in which peculiarities of colour or of form appear together in several groups not closely allied, but always among those inhabiting the same locality and as frequently among unprotected (that is, eatable) as among protected groups of butterflies; and I concluded, generally, as Mr. Bates had done, that these curious phenomena were due to "unknown local causes."

Thus the matter rested, till, in 1879 , Dr. Fritz Müller published in Kosmos a paper on "Ituna and Thyridia ; a remarkable case of Mimicry in Butterflies"; and in $188 \mathrm{r}$ a second paper, entitled "Remarkable cases of acquired resemblance among Butterflies," in which he gives a solution of the problem as really a case of mimicry. The first of these papers was translated by Mr. R. Meldola, and communicated to the Entomological Society of London in May, 1879 , and the same gentleman has kindly furnished me with a translation of the second paper (the title of which is given below), which discusses the whole question in great detail, and devotes much spa:e to a criticism of my suggested "unknown local causes" as a sufficient explanation of the phenomena. I may at once say that I admit this criticism to be sound; and that Dr. F. Müller's theory appears to me to afford a clue (with some slight modifications) to most of the cases of close individual resemblance of not-nearly-related species of butterflies yet observed. I therefore wish to state, as briefly as possible, the exact nature of the explanation now afforded us, and this is the more necessary because Dr. Müller's theory did not receive much support when brought before the Entomological Society, nor did it then satisfy Mr. Bates, the discoverer of the true meaning and importance of the phenomena of mimicry as interpreted by the doctrine of Natural Selection.

The explanation depends on the assumption, that some at least, if not all, young insectivorous birds learn by experience that the Heliconoid butterflies are distasteful, and in so doing sacrifice a certain number of individuals

I "Bemerkenswerthe Fälle erworbener Aehnlichkeit bei Schmetterlingen." Von Fritz Mül!er. (Separat-Abdruck aus "Kosmos," V. Jahrgang, I88r.) 